\title{
Partitioning of bovine lactoferrin in aqueous two-phase system containing poly(ethylene glycol) and sodium citrate
}

\author{
Angélica Ribeiro da Costa ${ }^{a, b}$, Jane Sélia dos Reis Coimbra ${ }^{b, e, *}$, \\ Luísa Alexandre Ferreira ${ }^{c}$, João Carlos Marcos ${ }^{d}$, \\ Igor José Boggione Santos ${ }^{b}$, Marleny D.A. Saldaña ${ }^{e}$, \\ José António Couto Teixeira ${ }^{\mathrm{C}}$ \\ a Departamento de Tecnologia Rural e Animal, Universidade Estadual do Sudoeste da Bahia, Praça Primavera, 40, \\ Bairro Primavera, 45700-000, Itapetinga, BA, Brasil \\ $\mathrm{b}$ Departamento de Tecnologia de Alimentos, Universidade Federal de Viçosa, Campus Universitário, s/n, Centro, \\ 36570-000, Viçosa, MG, Brasil \\ C IBB-Institute for Biotechnology and Bioengineering, Centre for Biological Engineering, Universidade do Minho, \\ Campus de Gualtar, 4710-057, Braga, Portugal \\ d Centro de Química, Universidade do Minho, Campus de Gualtar, 4710-057, Braga, Portugal \\ e Department of Agricultural, Food and Nutritional Science (AFNS), University of Alberta, T6G 2P5, Edmonton, AB, \\ Canada
}

\section{A R T I C L E I N F O}

\section{Article history:}

Received 23 March 2014

Received in revised form 21 March

2015

Accepted 8 April 2015

Available online 25 April 2015

\section{Keywords:}

ATPS

Molar mass

PEG

$\mathrm{pH}$

Phase diagram

Whey protein

\begin{abstract}
A B S T R A C T
The partitioning of the whey protein lactoferrin, which is an iron transporter glycoprotein, in an aqueous two-phase system composed of poly(ethylene glycol) (PEG) and sodium citrate was evaluated. Equilibrium data at $25^{\circ} \mathrm{C}$ were determined for each system studied using PEG with a molar mass of 1000 and $4000 \mathrm{~g} \mathrm{~mol}^{-1}$ at pH values of 5.5, 6.5, and 7.5. An increase in the molar mass of the polymer promoted the expansion of the two-phase region and caused the migration of the lactoferrin to the salt-rich bottom phase. An increase in $\mathrm{pH}$ also led to the expansion of the biphasic region. However, changing the $\mathrm{pH}$ over the tested range slightly affected protein partitioning. Lactoferrin recovery percentages greater than $94 \%$ were observed for all of the systems evaluated. The results indicated that lactoferrin can be successfully partitioned in an aqueous two-phase system formed of $14 \%$ (w/w) PEG and $10 \%(\mathrm{w} / \mathrm{w})$ sodium citrate at $\mathrm{pH} 5.5$ and $25^{\circ} \mathrm{C}$. The protein was concentrated 1000 -fold in the salt-rich bottom phase in this system.
\end{abstract}

(c) 2015 The Institution of Chemical Engineers. Published by Elsevier B.V. All rights reserved.

\section{Introduction}

New insights into purification strategies for biotechnological products are in demand to reduce production costs. Alternative bioseparation techniques are needed to (i) maintain biologically active molecules; (ii) achieve a high degree of purity and recovery; and (iii) be efficient, effective, and economical for large-scale processes. Aqueous two-phase systems (ATPS) are an alternative for separating, concentrating, and purifying biologically active molecules such as proteins in complex mixtures. ATPS are formed by mixing either two polymers (such as poly(ethylene glycol)/dextran) or one polymer

\footnotetext{
* Corresponding author at: Departamento de Tecnologia de Alimentos, Universidade Federal de Viçosa, Campus Universitário, s/n, Centro, 36570-000, Viçosa, MG, Brasil. Tel.: +55 31 38991618; fax: +55 3138992208.

E-mail addresses: jcoimbra@ufv.br, janeseliacoimbra@gmail.com (J.S.d.R. Coimbra). http://dx.doi.org/10.1016/j.fbp.2015.04.002

0960-3085/@ 2015 The Institution of Chemical Engineers. Published by Elsevier B.V. All rights reserved.
} 
and one salt (such as poly(ethylene glycol)/sodium phosphate) in water at a certain concentration and temperature. The two phases consist primarily of water (between $70 \%$ and $90 \%$ ) and provide an adequate environment with favourable conditions for biomolecule distribution, in addition to a low cost of implementation and ease of scale-up (Albertsson, 1986; Coimbra and Teixeira, 2010; Zaslavsky, 1995).

ATPS are used to concentrate and purify whey proteins (Alves et al., 2000; Anandharamakrishnan et al., 2005; Capezio et al., 2005; Silva et al., 2009). These proteins have high biological and functional value and confer technological and nutritional properties to food products. Lactoferrin (Lf) is an important whey protein because of its (i) anti-inflammatory, antimicrobial, antioxidant, and immunomodulatory properties; (ii) association with other biological functions, such as anticancer, proteolytic, and enzymatic activities; and (iii) use as a food supplement, such as in infant formula, yoghurt, skim milk, drinks, and pet foods, in skin care and personal hygiene products, such as lotions, creams, and face wash, moisturisers, and antioxidants; and in oral care products, such as mouthwash, mouth gels, toothpaste, and chewing gum (Baker and Baker, 2005; Coimbra and Teixeira, 2010; Moore et al., 1997; Steijns and van Hooijdonk, 2000; Ward et al., 2005).

Lactoferrin and bovine lactotransferrin belong to the group of glycoproteins that are known as transferrins, which have a molar mass of approximately $80,000 \mathrm{Da}$ with 689 amino acid residues, including all of the essential amino acids. Because of its capacity to reversibly bind to iron ions, lactoferrin occurs in two forms: hololactoferrin, which is saturated with iron, and apolactoferrin, which does not contain metal and is predominantly found in milk (Baker and Baker, 2005; Moore et al., 1997; Steijns and van Hooijdonk, 2000; Ward et al., 2005). Lactoferrin has a highly alkaline character with a $\mathrm{pH}$ between 8 and 9, probably due to three important concentrations of positive charges in its basic residues: (1) at the $\mathrm{N}$-terminal region (residues 1-7); (2) along the outside of the first helix (residues 13-30); and (3) in the inter-lobe region, close to the connecting helix (Baker and Baker, 2005).

Knowledge of the equilibrium data for a system is required to successfully use ATPS to partition lactoferrin. The literature contains equilibrium data for various polymer-polymer ATPS, such as poly(ethylene glycol) (PEG) + dextran (Albertsson, 1986), PEG + maltodextrin (Machado et al., 2012), PEG + (ficoll, ucon, or hydroxypropyl starch) (Madeira et al., 2008); and polymer-salt, such as PEG + potassium phosphate (Silva et al., 1997), PEG + citrate salts (Marcos et al., 1999; Oliveira et al., 2008b; Tubío et al., 2006), PEG + sulphate salts (Oliveira et al., 2008a). Polymer-salt ATPS are the most commonly used systems for biomolecule partitioning because of the greater differences in density and viscosity among the phases, which reduces the phase splitting time and allows for the easier handling of the phases. ATPS equilibrium parameters are affected by the nature of the added salt and polymer, by the $\mathrm{pH}$ and temperature of the system, and by the presence of other compounds (Albertsson, 1986; Coimbra and Teixeira, 2010; Zaslavsky, 1995). An aqueous two-phase system that has potential for lactoferrin partitioning is a system composed of PEG and sodium citrate. It should be emphasised that sodium citrate is biodegradable and non-toxic and can be discharged from plants for biological wastewater treatment (Silva et al., 2009). The transfer of lactoferrin between the phases can be evaluated by using the protein partition coefficient, which is defined as the ratio of the protein concentration in the top phase to that in the bottom phase. Several factors, such as temperature, $\mathrm{pH}$, system composition, the molar mass of the polymer, and the ionic species, as well as the specific characteristics of the lactoferrin (size, hydrophobicity, and surface charge) influence the protein transfer between the phases (Ferreira et al., 2011; Nascimento et al., 2010; Oliveira et al., 2009; Porto et al., 2011).

The objectives of this study were to evaluate the partitioning of lactoferrin in aqueous two phase systems composed of poly(ethylene glycol) and sodium citrate and to characterise the system according to the polymers with average molar masses of 1000 and $4000 \mathrm{~g} \mathrm{~mol}^{-1}$, a polymer concentration between $14 \%$ and $21 \%(\mathrm{w} / \mathrm{w})$, and $\mathrm{pH}$ values of $5.5,6.5$, and 7.5 at $25^{\circ} \mathrm{C}$. Binodal curves and tie-lines for the studied systems were also obtained.

\section{Materials and methods}

\subsection{Chemicals}

Lactoferrin was donated by FrieslandCampina DMV (Veghel, Nederland). Poly(ethylene glycol) (PEG) with average molar masses of $1000 \mathrm{~g} \mathrm{~mol}^{-1}$ (PEG1000) and $4000 \mathrm{~g} \mathrm{~mol}^{-1}$ (PEG4000) were purchased from Sigma-Aldrich (St. Louis, MA, USA) and Merck (Darmstadt, Germany). Sodium citrate was supplied by Riedel-de Haën (Seelze, Germany), and citric acid monohydrate was obtained from Pronalab (Lisbon, Portugal). All chemicals were of analytical grade and used without further purification. Double distilled and deionised water was used in all experiments (Milli-Q, Millipore Inc., Bedford, MA, USA; $18.2 \mathrm{M} \Omega \mathrm{cm}$ )

\subsection{Equilibrium data}

Phase diagrams were characterised by binodal curves and tielines. Binodal curves were determined using the cloud point method (Ferreira and Teixeira, 2011). Stock solutions of PEG (1000 and 4000; 50\% w/w) were prepared and then stored at $4{ }^{\circ} \mathrm{C}$. Concentrated solutions $(35.3 \%, \mathrm{w} / \mathrm{w})$ of sodium citrate at $\mathrm{pH}$ values of $5.5,6.5$, and 7.5 were prepared by adding a citric acid monohydrate solution $\left(1.2 \mathrm{~mol} \mathrm{~kg}^{-1}\right)$ to tri-sodium citrate dehydrate solution $\left(1.2 \mathrm{~mol} \mathrm{~kg}^{-1}\right)$ until the desired $\mathrm{pH}$ was reached (CRISON, MicroTT 2050, Spain). The system pH was measured and was close to the $\mathrm{pH}$ of the stock citrate solution.

Appropriate amounts of PEG solution, citrate solution, and water were mixed in glass tubes to obtain a heterogeneous system ( $2 \mathrm{~g}$ total mass). The tubes were vigorously shaken and kept in a thermostatic water bath (Grant Instruments, England) at $(25 \pm 0.1)^{\circ} \mathrm{C}$ for $20 \mathrm{~min}$. Subsequently, a known amount of water was added to the tube until a homogeneous system was obtained. Additional binodal points were obtained by adding sufficient PEG stock solution dropwise to produce turbidity, followed by the addition of a small amount of water to clarify the system. Weighing was done using an analytical balance (Ohaus, Explorer Pro, Model EP214DC, Switzerland) that was accurate to $\pm 0.2 \mathrm{mg}$.

The initial composition of the mixture used to construct the binodal curve (PEG, citrate, and water) and the amount of PEG or water added (to produce turbidity or to clarify the system) to the mixture were used to calculate the total system composition, which provided the points in the binodal curve. Each observed binodal curve was adjusted to the empirical Eq. (1) as follows (Merchuk et al., 1998):

$y=\operatorname{aexp}\left(b x^{0.5}-c x^{3}\right)$ 
where, $y$ and $x$ are the respective polymer and salt compositions (mass fraction), and $a, b$, and $c$ are adjustable parameters without a clear physical meaning. These parameters were obtained by least-squares regression.

The end points of the tie-lines (nodes) were obtained experimentally by analysing the composition of the conjugated phases at equilibrium. ATPS with compositions listed in Table 1 were prepared (\% w/w) in $15 \mathrm{~mL}$ graduated tubes to achieve a total system mass of $15 \mathrm{~g}$. The mixture was shaken vigorously, centrifuged for $10 \mathrm{~min}$ at $1470 \times \mathrm{g}$ (Hermle Z36HK, Germany) to accelerate phase settling, and then allowed to equilibrate in a thermostatic water bath for at least $24 \mathrm{~h}$. The volume of the top and bottom phases was measured in a graduated cylinder. The phases were withdrawn with a pipette for the upper phase and a syringe with a long, thin needle for the lower phase. The density of each phase was obtained with a pycnometer that had previously been calibrated with water at $25^{\circ} \mathrm{C}$.

Citrate was quantified by isocratic elution using high performance liquid chromatography (Jasco equipment, AS2057 plus, PU880, UV270 plus, Japan). Samples were injected with a $20 \mu \mathrm{L}$ loop. The column was a Varian MetaCarb $67 \mathrm{H}$ (300 mm $\times 6.5 \mathrm{~mm}$ ) (USA), with a Chrompack (Nederlands) column heater $\left(60^{\circ} \mathrm{C}\right)$. The mobile phase was $0.01 \mathrm{~N}$ sulphuric acid, with a flow rate of $0.7 \mathrm{~mL} \mathrm{~min}^{-1}$. The eluent was monitored by UV absorption at $210 \mathrm{~nm}$. The citrate concentration was calculated from a standard curve.

The PEG concentration was determined via the measurement of the refractive index of each phase (Bellingham + Stanley Limited, England). Because the refractive index is an additive property, the PEG concentration was determined after correcting each reading for the citrate contribution. The corrections were made using linear standard curves for the salt. These standard curves were determined separately for aqueous solutions of PEG1000 and PEG4000 with concentrations between ( 1 and 50$) \%(w / w)$ and for salt with concentrations between $(0.05$ and 1$) \mathrm{mol} \mathrm{L}^{-1}$. Because the citrate was quantified by the chromatographic method described above, the salt refractive indices were used as independent terms in the standard curve constructed for the polymer. Mass balance was used to calculate the water content in each phase. All determinations were performed in duplicate.

The tie-line length (TLL) and the slope of the tie-line (STL) were calculated according to Eqs. (2) and (3),

$\mathrm{TLL}=\sqrt{\Delta \mathrm{P}^{2}+\Delta \mathrm{S}^{2}}$

$\mathrm{STL}=\frac{\Delta \mathrm{P}}{\Delta \mathrm{S}}$

where, $\Delta P$ is the difference in the PEG concentration between the top and bottom phases and $\Delta S$ is the difference in the salt concentration between the top and bottom phases.

\subsection{Lactoferrin partitioning in aqueous two-phase systems}

ATPS with the same composition defined in Section 2.2 were prepared. Appropriate amounts of PEG stock solutions, citrate, water, and lactoferrin were weighed using a balance with a precision of $\pm 0.2 \mathrm{mg}$ (Ohaus, Explorer Pro, Model EP214DC, Switzerland), to obtain a total mass of $5.0 \mathrm{~g}$ for the desired system composition. In all systems, the lactoferrin concentration was equal to $0.5 \mathrm{mg} \mathrm{mL}^{-1}$ at the global point. The amount of lactoferrin in the system was three times the concentration in the whey to ensure the reliability of the results. After mixing by manual inversion for $1 \mathrm{~min}$, the system was centrifuged at $1470 \times \mathrm{g}$ for $10 \mathrm{~min}$ (Hermle Z36HK, Germany) to achieve complete phase separation. Subsequently, the tubes containing ATPS were maintained in a thermostatic bath (Grant Instruments, England) at $(25 \pm 0.1)^{\circ} \mathrm{C}$ for $20 \mathrm{~h}$. After reaching thermodynamic equilibrium, the volume of each phase was measured, and a sample of each phase was removed for posterior quantification of the protein content. All experiments were performed in duplicate.

The protein was quantified according to the Bradford method (Bradford, 1976), using the Coomassie Plus reagent (Pierce, USA). The samples were placed on microplates (NUNC, Denmark) and the absorbance was monitored at $595 \mathrm{~nm}$ (microplate reader, Spectrophotometer Varian Cary 50, USA). A standard curve was determined from a pure lactoferrin solution at different concentrations. The interference of PEG and citrate on the protein measurement was corrected by using each phase without protein as a blank. The value for the protein concentration used in the calculations was the mean value of at least three measurements, with a minimum of two repetitions for each partition experiment.

The distribution of lactoferrin in each system was evaluated using the protein partitioning coefficient, $K_{\mathrm{P}}$, as expressed by Eq. (4):

$K_{P}=\frac{[\operatorname{Pr}]_{\text {Top }}}{[\operatorname{Pr}]_{\text {Bottom }}}$

where, $[\mathrm{Pr}]_{\text {Top }}$ and $[\mathrm{Pr}]_{\text {Bottom }}$ are the protein concentrations in the PEG-rich phase (top phase) and in the salt-rich phase (bottom phase), respectively. This coefficient can be interpreted as a measure of the level of protein separation via the extraction process.

To select the system with the greatest lactoferrin purification capacity, the theoretical protein recovery in the bottom phase, $y(\%)$, was calculated by using Eq. (5) (Oliveira et al., 2009):

$y(\%)=\frac{100}{1+\left(1 / R K_{P}\right)}$

where, $R$ corresponds to the ratio between the volume of the top and bottom phases. The experiments were performed in duplicate.

\section{Results and discussion}

\subsection{Equilibrium data}

Table 1 shows the equilibrium data, the tie-line length (TLL, Eq. (2)), and the slope of the tie-line (STL, Eq. (3)) for PEG (1000 and 4000) + sodium citrate ATPS as a function of the $\mathrm{pH}$ $(5.5,6.5$, and 7.5$)$ at $25^{\circ} \mathrm{C}$. The water content in each phase was calculated using the mass balance of the components $(\%$ PEG + \%salt + \%water $=100 \%)$.

As observed in Fig. 1, the binodal curve became more asymmetric and closer to the origin with increased polymer molar mass. Thus, the polymer molar mass increase caused the biphasic region increase. A similar behaviour of the binodal curves was also described for traditional PEG + phosphate systems (Silva et al., 1997) and for PEG + citrate systems (Marcos 
Table 1 - Tie-line length, equilibrium data, and tie-line slope for PEG + sodium citrate ATPS at $25^{\circ} \mathrm{C}$. Equilibrium data $(\% \mathrm{w} / \mathrm{w})$

\begin{tabular}{|c|c|c|c|c|c|c|c|c|}
\hline & \multirow{3}{*}{ TLL } & \multicolumn{6}{|c|}{ Equilibrium data (\% w/w) } & \multirow{3}{*}{ STL } \\
\hline & & \multicolumn{2}{|c|}{ Global point } & \multicolumn{2}{|c|}{ Top phase } & \multicolumn{2}{|c|}{ Bottom phase } & \\
\hline & & Salt & PEG & Salt & PEG & Salt & PEG & \\
\hline & & \multicolumn{7}{|c|}{ PEG1000, pH 5.5} \\
\hline 1 & 25.20 & 14.00 & 17.00 & 8.85 & 24.53 & 22.91 & 3.64 & -1.49 \\
\hline 2 & 37.60 & 15.00 & 18.00 & 6.61 & 31.03 & 29.03 & 0.81 & -1.35 \\
\hline \multirow[t]{2}{*}{3} & 43.40 & 16.00 & 19.00 & 5.98 & 35.53 & 31.17 & 0.19 & -1.40 \\
\hline & & \multicolumn{7}{|c|}{ PEG1000, pH 6.5} \\
\hline 1 & 34.20 & 13.00 & 18.00 & 6.52 & 29.74 & 25.22 & 1.15 & -1.53 \\
\hline 2 & 41.70 & 14.00 & 19.00 & 4.98 & 34.08 & 29.39 & 0.26 & -1.39 \\
\hline \multirow[t]{2}{*}{3} & 46.10 & 15.00 & 20.00 & 4.6 & 37.76 & 31.26 & 0.12 & -1.41 \\
\hline & & \multicolumn{7}{|c|}{ PEG1000, pH 7.5} \\
\hline 1 & 30.20 & 12.00 & 19.00 & 6.82 & 28.66 & 22.06 & 2.54 & -1.71 \\
\hline 2 & 40.90 & 13.00 & 20.00 & 5.2 & 33.63 & 28.93 & 0.26 & -1.41 \\
\hline \multirow[t]{2}{*}{3} & 45.50 & 14.00 & 21.00 & 4.27 & 37.32 & 30.27 & 0.13 & -1.41 \\
\hline & & \multicolumn{7}{|c|}{ PEG4000, pH 5.5} \\
\hline 1 & 32.00 & 10.00 & 14.00 & 5.13 & 22.20 & 18.22 & 0.13 & -1.69 \\
\hline 2 & 37.10 & 10.50 & 16.00 & 3.99 & 27.23 & 20.68 & 0.03 & -1.63 \\
\hline \multirow[t]{2}{*}{3} & 42.70 & 11.00 & 18.00 & 3.25 & 29.78 & 23.72 & 0,00 & -1.46 \\
\hline & & \multicolumn{7}{|c|}{ PEG4000, pH 6.5} \\
\hline 1 & 29.20 & 11.00 & 14.00 & 5.06 & 24.30 & 21.58 & 0.18 & -1.46 \\
\hline 2 & 32.30 & 11.50 & 16.00 & 4.03 & 26.53 & 22.55 & 0.05 & -1.43 \\
\hline \multirow[t]{2}{*}{3} & 37.80 & 12.00 & 18.00 & 3.11 & 30.13 & 25.99 & 0,00 & -1.32 \\
\hline & & \multicolumn{7}{|c|}{ PEG4000, pH 7.5} \\
\hline 1 & 25.70 & 12.00 & 17.00 & 4.94 & 27.14 & 22.65 & 0.48 & -1.51 \\
\hline 2 & 31.90 & 12.50 & 18.00 & 4.45 & 31.08 & 24.92 & 0.15 & -1.51 \\
\hline 3 & 36.10 & 13.00 & 19.00 & 4.11 & 35.42 & 28.05 & 0.02 & -1.49 \\
\hline
\end{tabular}

et al., 1999; Tubío et al., 2006). Such behaviour might be due to the increase in the incompatibility among components of the system after mixing. Therefore, a tendency towards a lower quantity of components in promoting phase splitting was observed with an increase of component incompatibility in the system. This tendency was more pronounced in systems that contained a high concentration of sodium citrate and PEG with a high molar mass due to an increase in the hydrophobic characteristics of the system.

In Fig. 1, the binodal curves show similar shapes at all tested $\mathrm{pH}$ values. The ratio between trivalent and divalent citrate ions $\left(\mathrm{pK}_{\mathrm{a}}=6.4\right)$ increases with the increase in the $\mathrm{pH}$ value. Because trivalent ions are more effective in phase

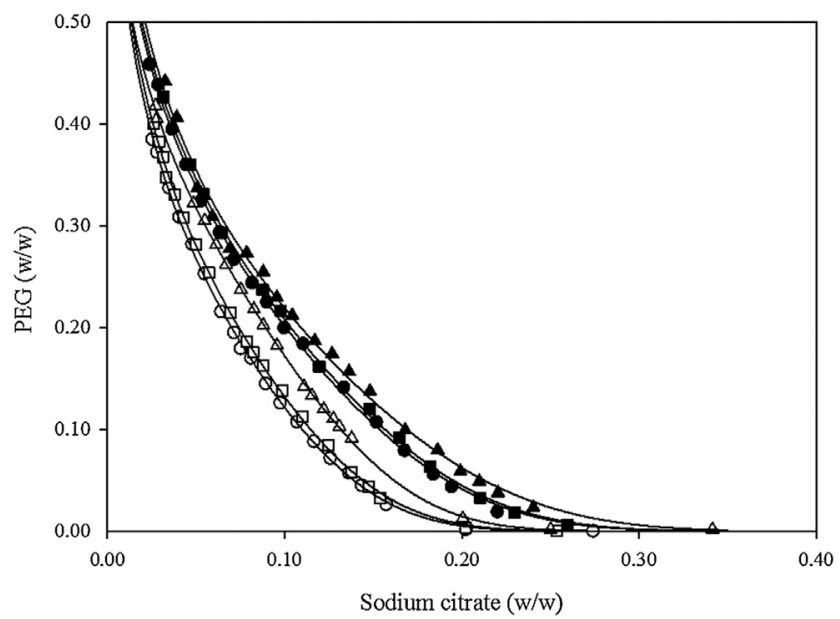

Fig. 1 - Binodal curves at $25^{\circ} \mathrm{C}$. PEG1000 + sodium citrate ATPS: pH $5.5(\Delta), 6.5(\square)$, and $7.5(0)$; PEG4000 + sodium citrate ATPS: pH $5.5(\Delta), 6.5(\square)$, and $7.5(O)$. separation, smaller citrate concentrations were necessary for the two-phase formation, which is in agreement with the results of Marcos et al. (Marcos et al., 1999).

Fig. 2 illustrates the tie-line behaviour for PEG4000 + citrate ATPS $\left(5.5 \mathrm{pH}\right.$ and $25^{\circ} \mathrm{C}$ ) and the corresponding linear regression model for each tie-line.

For each ATPS, the Merchuk equation (Merchuk et al., 1998) was successfully used to adjust the experimental data for the binodal curve. Coefficients a, b, and c of Eq. (1) and the coefficients of determination $\left(r^{2}\right)$ are given in Table 2. The exclusion of PEG from the salt-rich bottom phase can be observed. Similar results have been reported in the literature (Machado et al., 2012; Silva et al., 1997).

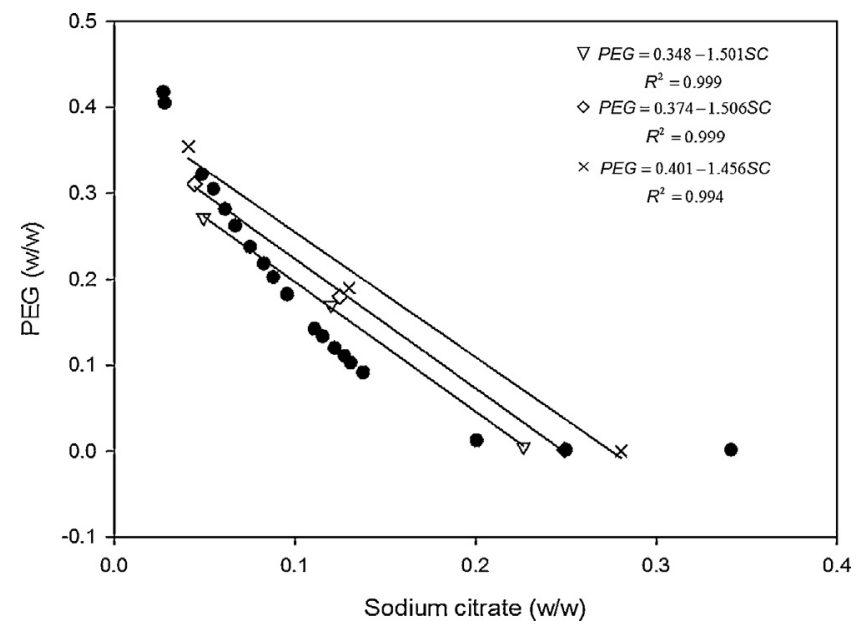

Fig. 2 - Tie-line behaviour of PEG4000 + sodium citrate ATPS at $5.5 \mathrm{pH}$ and $25^{\circ} \mathrm{C}$ (SC-sodium citrate). 
Table 2 - Empirical coefficients and determination coefficients $\left(r^{2}\right)$ of Eq. (1) for PEG + sodium citrate ATPS at $25^{\circ}$ C.

\begin{tabular}{lcccc} 
pH & $a$ & $b$ & $c$ & $r^{2}$ \\
\hline PEG 1000 & & & & \\
5.5 & $0.887 \pm 0.018$ & $-4.222 \pm 0.099$ & $146.465 \pm 7.695$ & 0.999 \\
6.5 & $0.933 \pm 0.049$ & $-4.262 \pm 0.226$ & $99.928 \pm 11.486$ & 0.995 \\
7.5 & $0.898 \pm 0.029$ & $-4.183 \pm 0.143$ & $140.577 \pm 8.327$ & 0.999 \\
PEG 4000 & & & $352.295 \pm 14.043$ & 0.999 \\
5.5 & $0.893 \pm 0.019$ & $-5.189 \pm 0.110$ & $327.145 \pm 16.215$ & 0.999 \\
6.5 & $0.904 \pm 0.022$ & $-5.043 \pm 0.126$ & $276.656 \pm 9.014$ & 0.999 \\
7.5 & $0.807 \pm 0.031$ & $-4.007 \pm 0.081$ & \\
\hline
\end{tabular}

\subsection{Lactoferrin partitioning experiments}

\subsubsection{Partition coefficient}

Table 3 shows data for the partition coefficient, the top phase volume, the bottom phase volume, the volume phase ratio, and the theoretical recovery of lactoferrin in the bottom phase for different values of $\mathrm{pH}$ and tie-line length. The protein was concentrated in the salt-rich bottom phase $\left(K_{\mathrm{P}}<1\right)$ with a recovery percentage higher than $94 \%$ for all of the systems studied.

The protein was characterised by partition coefficients less than 1 , which indicated a greater affinity with the bottom phase. However, a direct relationship between the volume phase ratio and the partition coefficient was not observed, likely due to the simultaneous influence of other thermodynamic variables on the partitioning, e.g., the component concentration and the $\mathrm{pH}$ value. In contrast, lower values of $K_{\mathrm{P}}$ were associated with higher theoretical recovery values.

A wide range of $K_{P}$ has been reported for other bovine whey proteins. For instance, PEG + sodium citrate ATPS were used to partition glycomacropeptide with a $K_{P}$ of 33.41 (Silva et al., 2009). PEG 1500 + potassium phosphate ATPS were used to partition $\alpha$-lactalbumin and $\beta$-lactoglobulin with $K_{P}$ values of 12.614 and 0.063 (Rojas et al., 2004), and 8.0 and 0.056 (Alves et al., 2000), respectively. PEG $1500+$ potassium phosphate ATPS were used to partition BSA, $\alpha$-lactalbumin, and $\beta$-lactoglobulin, with a $K_{P}$ of 10,27 , and 0.07 , respectively (Capezio et al., 2005).

3.2.1.1. Influence of the ATPS composition on $K_{P}$. Two molar masses of PEG at three different global compositions and $\mathrm{pH}$ values were prepared for each PEG-citrate ATPS to evaluate the relationship between $K_{P}$ and the biphasic system composition. The influence of the molar mass of the polymer on protein partitioning has been shown by various researchers (Albertsson, 1986; Azevedo et al., 2009; Boaglio et al., 2006; Coimbra and Teixeira, 2010; Marcos et al., 1999; Nascimento et al., 2010; Oliveira et al., 2009; Porto et al., 2011; Tubío et al., 2006; Zaslavsky, 1995). From Table 3, lactoferrin partitioning in PEG + citrate ATPS is affected by the molar mass of PEG. The extent of lactoferrin partitioning was lower for PEG that had a lower molar mass $\left(1000 \mathrm{~g} \mathrm{~mol}^{-1}\right)$. PEG 4000 + citrate ATPS yielded the most appropriate $K_{P}$ values for the lactoferrin separation, which ranged from 0.019 to 0.001 . In such ATPS, the lactoferrin concentration in the salt-rich bottom phase was 52 to 1000 times higher than that in the polymer-rich top phase. Another important factor to consider is the volume phase ratio. For all systems studied, the volume of the phases was approximately equal. Along the same tie-line, $K_{P}$ remained constant if the volume phase ratio was changed by increasing the salt-rich phase volume. However, the protein migration to the salt-rich phase showed a higher increase. Thus, PEG + citrate ATPS are potentially useful for effective lactoferrin recovery. For most ATPS analysed, an increment in the lactoferrin partition coefficient was observed with the quantities of polymer and salt present in the system were increased (and consequently, the TLL increased).

Biomolecule partitioning depends on a number of factors such as hydrophobic properties, the addition of salts, the electrical potential between phases, molecular size, and molecular configuration. The hydrophobic effect is defined as an unfavourable interaction between nonpolar substances or moieties of molecules with water. The hydrophobic effect can be responsible for the low solubility of some biomolecules (Silva et al., 2007). In all ATPS, lactoferrin showed a strong tendency to become concentrated in the salt-rich bottom phase $\left(K_{\mathrm{P}}<1\right)$ (Fig. 2). Such behaviour indicates that the lactoferrin is strongly hydrophilic because the hydrophobicity of the PEG-rich top phase is higher than that of the bottom phase (Carneiro-da-Cunha et al., 2014). Generally, positively charged proteins selectively partition to the bottom phase, whereas negatively charged proteins prefer to migrate to the top phase in a PEG/salt ATPS (Albertsson, 1986). The lactoferrin molecule had a net positive charge $(\mathrm{pI} \sim 8.5)$ over the $\mathrm{pH}$

Table 3 - Top phase volume $\left(V_{t}, \mathrm{~mL}\right)$, bottom phase volume $\left(V_{b}, m L\right)$, volume phase ratio $\left(V_{t} / V_{b}\right)$, lactoferrin partition coefficient $\left(\mathrm{K}_{\mathrm{p}}\right)$, lactoferrin theoretical recovery $y$ (in the bottom phase, \%) for PEG + sodium citrate ATPS as affected by pH, tie-line length, and PEG molar mass at $25^{\circ} \mathrm{C}$.

\begin{tabular}{|c|c|c|c|c|c|c|c|c|c|c|c|}
\hline \multirow[t]{2}{*}{$\mathrm{pH}$} & \multirow[t]{2}{*}{ TLL } & \multicolumn{5}{|c|}{ PEG1000 } & \multicolumn{5}{|c|}{ PEG4000 } \\
\hline & & $\mathrm{V}_{\mathrm{t}}$ & $V_{b}$ & $\mathrm{~V}_{\mathrm{t}} / \mathrm{V}_{\mathrm{b}}$ & $K_{\mathrm{p}}$ & $y(\%)$ & $\mathrm{V}_{\mathrm{t}}$ & $\mathrm{V}_{\mathrm{b}}$ & $\mathrm{V}_{\mathrm{t}} / \mathrm{V}_{\mathrm{b}}$ & $K_{\mathrm{p}}$ & $y(\%)$ \\
\hline \multirow[t]{3}{*}{5.5} & 1 & 2.68 & 1.95 & 1.38 & 0.017 & $97.69 \pm 0.25$ & 2.38 & 2.17 & 1.10 & 0.001 & $99.84 \pm 0.05$ \\
\hline & 2 & 2.60 & 2.02 & 1.29 & 0.018 & $97.69 \pm 0.02$ & 2.44 & 2.00 & 1.23 & 0.013 & $98.38 \pm 0.35$ \\
\hline & 3 & 2.55 & 2.01 & 1.27 & 0.019 & $97.59 \pm 0.06$ & 2.64 & 1.95 & 1.36 & 0.019 & $97.51 \pm 0.01$ \\
\hline \multirow[t]{3}{*}{6.5} & 1 & 2.57 & 2.06 & 1.25 & 0.025 & $96.90 \pm 0.50$ & 2.68 & 1.99 & 1.35 & 0.002 & $99.78 \pm 0.03$ \\
\hline & 2 & 2.69 & 1.82 & 1.48 & 0.030 & $95.71 \pm 0.58$ & 2.41 & 2.14 & 1.12 & 0.002 & $99.73 \pm 0.04$ \\
\hline & 3 & 2.64 & 1.95 & 1.36 & 0.020 & $97.34 \pm 0.39$ & 2.51 & 2.00 & 1.26 & 0.013 & $98.33 \pm 0.21$ \\
\hline \multirow[t]{3}{*}{7.5} & 1 & 3.03 & 1.64 & 1.84 & 0.021 & $96.31 \pm 0.17$ & 2.79 & 1.87 & 1.50 & 0.011 & $98.32 \pm 0.00$ \\
\hline & 2 & 2.98 & 1.54 & 1.94 & 0.028 & $94.80 \pm 0.76$ & 2.80 & 1.91 & 1.47 & 0.011 & $98.48 \pm 0.06$ \\
\hline & 3 & 2.80 & 1.79 & 1.56 & 0.030 & $95.53 \pm 0.34$ & 2.75 & 1.88 & 1.47 & 0.009 & $98.72 \pm 0.06$ \\
\hline
\end{tabular}


range studied $(5.5,6.5$, and 7.5$)$, which favoured electrostatic interactions between the protein and the negatively charged citrate ions and confirmed that the direction of the protein partitioning was in agreement with the experimental results. Similar observations have been reported for the partitioning of other molecules. For example, Azevedo et al. (2009) used PEG + citrate ATPS to partition human IgG and observed that IgG migrates almost exclusively to the bottom phase in the absence of an added salt ( $\mathrm{NaCl}$ ). Boaglio et al. (2006) described the affinity of $\beta$-lactoglobulin, bovine serum albumin, and alpha-1 antitrypsin for the citrate rich-phase in a PEG + citrate ATPS.

In addition, the protein transfer to one of the system phases requires breaking the interaction between the phase components to create a cavity where the protein can fit. Therefore, the energy balance can be negative or positive, depending on whether the protein/polymer interactions are attractive or repulsive. These interactions can be expressed by using the thermodynamic parameter Gibbs free energy $\left(\Delta G^{\circ}\right)$. Generally, entropy contributions cause the protein to partition to the phase that has the greatest concentration of water molecules. During the protein partitioning in an ATPS composed of a polymer/electrolyte mixture, entropic forces act to concentrate the biopolymer in the salt-rich bottom phase due to its greater numerical density (Johansson et al., 1998). The bottom phase has a greater number of molecules by volume unity than does the polymeric-rich top phase, which is mainly attributed to the higher water content in the saline phase (Table 2).

\section{Conclusion}

Equilibrium data for aqueous two-phase systems formed by PEG 1000 + sodium citrate and PEG 4000 + sodium citrate were determined at $\mathrm{pH}$ values of $5.5,6.5$, and 7.5. In general, the biphasic region was observed to shift in the direction of the origin axes with an increase in the molar mass of the polymer. In fact, the higher the polymer molar mass was, the lower the amount of salt was necessary to induce the phase splitting. The lactoferrin partitioning behaviour in a PEG-citrate ATPS indicated that the protein was extracted into the salt-rich bottom phase. The best ATPS condition for lactoferrin partitioning was $10 \%(\mathrm{w} / \mathrm{w})$ PEG4000 and $14 \%(\mathrm{w} / \mathrm{w})$ sodium citrate (pH 5.5), which concentrated the protein 1000 -fold in the saltrich bottom phase. Considering the potential for industrial applications of isolated lactoferrin in food and in therapeutic fields, the results of this work are relevant for the downstream process design of protein purification.

\section{Acknowledgements}

The authors acknowledge the Brazilian agencies FAPESB, CNPq, and FAPEMIG for their financial support. Angelica R. da Costa and Jane Coimbra thank Professor JA Teixeira for his support at DEB/Minho University/Portugal.

\section{References}

Albertsson, P.A., 1986. Partition of Cell Particles and Macromolecules, 3rd ed. Wiley, New York.

Alves, J.G., Chumpitaz, L.D., da Silva, L.H., Franco, T.T., Meirelles, A.J., 2000. Partitioning of whey proteins, bovine serum albumin and porcine insulin in aqueous two-phase systems. J. Chromatogr. B 743, 235-239.
Anandharamakrishnan, C., Raghavendra, S.N., Barhate, R.S., Hanumesh, U., Raghavarao, K.S.M.S., 2005. Aqueous two-phase extraction for recovery of proteins from cheese whey. Food Bioprod. Process. 83, 191-197, http://dx.doi.org/10.1205/fbp.03403.

Azevedo, A.M., Gomes, A.G., Rosa, P.A.J., Ferreira, I.F., Pisco, A.M.M.O., Aires-Barros, M.R., 2009. Partitioning of human antibodies in polyethylene glycol-sodium citrate aqueous two-phase systems. Sep. Purif. Technol. 65, 14-21, http://dx.doi.org/10.1016/j.seppur.2007.12.010.

Baker, E.N., Baker, H.M., 2005. Molecular structure, binding properties and dynamics of lactoferrin. Cell. Mol. Life Sci. 62, 2531-2539, http://dx.doi.org/10.1007/s00018-005-5368-9.

Boaglio, A., Bassani, G., Picó, G., Nerli, B., 2006. Features of the milk whey protein partitioning in polyethyleneglycol-sodium citrate aqueous two-phase systems with the goal of isolating human alpha-1 antitrypsin expressed in bovine milk. J. Chromatogr. B 837, 18-23, http://dx.doi.org/10.1016/j.jchromb.2006.03.049.

Bradford, M.M., 1976. A rapid and sensitive method for the quantitation of microgram quantities of protein utilizing the principle of protein-dye binding. Anal. Biochem. 72, 248-254, http://dx.doi.org/10.1016/0003-2697(76)90527-3.

Capezio, L., Romanini, D., Picó, G.A., Nerli, B., 2005. Partition of whey milk proteins in aqueous two-phase systems of polyethylene glycol-phosphate as a starting point to isolate proteins expressed in transgenic milk. J. Chromatogr. B 819, 25-31, http://dx.doi.org/10.1016/j.jchromb.2005.01.020.

Carneiro-da-Cunha, M.N., Souza, K.P.S., Mota, a.M.O., Teixeira, J.A., Porto, C.S., Porto, T.S., Porto, a.L.F., 2014. Stability of clavulanic acid in PEG/citrate and liquid-liquid extraction in aqueous two-phase system. Fluid Phase Equilib. 375, 104-109, http://dx.doi.org/10.1016/j.fluid.2014.04.036.

Coimbra, J.S.R., Teixeira, J.A., 2010. Engineering Aspects of Milk and Dairy Products. Taylor \& Francis, Boca Raton.

Ferreira, L., Teixeira, J., 2011. Salt effect on the aqueous two-phase system PEG 8000-sodium sulfate. J. Chem. Eng. Data 56, 133-137.

Ferreira, L.A., Teixeira, J.A., Mikheeva, L.M., Chait, A., Zaslavsky, B.Y., 2011. Effect of salt additives on partition of nonionic solutes in aqueous PEG-sodium sulfate two-phase system. J. Chromatogr. A 1218, 5031-5039, http://dx.doi.org/10.1016/j.chroma.2011.05.068.

Johansson, H.-O., Karlström, G., Tjerneld, F., Haynes, C.A., 1998. Driving forces for phase separation and partitioning in aqueous two-phase systems. J. Chromatogr. B 711, 3-17, http://dx.doi.org/10.1016/S0378-4347(97)00585-9.

Machado, F.L.C., Coimbra, J.S.R., Zuniga, A.D.G., Costa, A.R., Martins, J.P., 2012. Equilibrium data of aqueous two-phase systems composed of poly(ethylene glycol) and maltodextrin. J. Chem. Eng. Data 57, 1984-1990, http://dx.doi.org/10.1021/je3002442.

Madeira, P.P., Teixeira, J.A., Macedo, E.A., Mikheeva, L.M. Zaslavsky, B.Y., 2008. "On the collander equation": protein partitioning in polymer/polymer aqueous two-phase systems. J. Chromatogr. A 1190, 39-43.

Marcos, J., Fonseca, L., Ramalho, M., Cabral, J.M., 1999. Partial purification of penicillin acylase from Escherichia coli in poly(ethylene glycol)-sodium citrate aqueous two-phase systems. J. Chromatogr. B 734, 15-22, http://dx.doi.org/10.1016/S0378-4347(99)00319-9.

Merchuk, J.C., Andrews, B.A., Asenjo, J.A., 1998. Aqueous two-phase systems for protein separation. J. Chromatogr. B 711, 285-293, http://dx.doi.org/10.1016/S0378-4347(97)00594-X.

Moore, S.A., Anderson, B.F., Groom, C.R., Haridas, M., Baker, E.N., 1997. Three-dimensional structure of diferric bovine lactoferrin at 2.8 A resolution. J. Mol. Biol. 274, 222-236, http://dx.doi.org/10.1006/jmbi.1997.1386.

Nascimento, I.S.B., Coimbra, J.S., dos, R., Martins, J.P., da Silva, L.H.M., Bonomo, R.C.F., Pirozzi, M.R., Cinquini, A., 2010. Partitioning of glutenin flour of special wheat using aqueous two-phase systems. J. Cereal Sci. 52, 270-274, http://dx.doi.org/10.1016/j.jcs.2010.06.005. 
Oliveira, F.C., Coimbra, J.S.R., da Silva, L.H.M., Rojas, E.E.G., da Silva, M., do, C.H., 2009. Ovomucoid partitioning in aqueous two-phase systems. Biochem. Eng. J. 47, 55-60, http://dx.doi.org/10.1016/j.bej.2009.07.002.

Oliveira, R.M., Coimbra, J.S.R., Francisco, K.R., Minim, L.A., da Silva, L.H.M., Pereira, J.A.M., 2008a. Liquid-liquid equilibrium of aqueous two-phase systems containing poly(ethylene) glycol 4000 and zinc sulfate at different temperatures. J. Chem. Eng. Data 53, 919-922, http://dx.doi.org/10.1021/ je700493t.

Oliveira, R.M., Coimbra, J.S.R., Minim, L.A., da Silva, L.H.M., Ferreira Fontes, M.P., 2008b. Liquid-Liquid equilibria of biphasic systems composed of sodium citrate + polyethylene(glycol) 1500 or 4000 at different temperatures. J. Chem. Eng. Data 53, 895-899, http://dx.doi.org/10.1021/je7004209.

Porto, C.S., Porto, T.S., Nascimento, K.S., Teixeira, E.H., Cavada, B.S., Lima-Filho, J.L., Porto, A.L.F., 2011. Partition of lectin from Canavalia grandiflora Benth in aqueous two-phase systems using factorial design. Biochem. Eng. J. 53, 165-171, http://dx.doi.org/10.1016/j.bej.2010.10.006.

Rojas, E.E.G., Coimbra, J.S.R., Minim, L.A., Zuniga, A.D.G., Saraiva, S.H., Minim, V.P.R., 2004. Size-exclusion chromatography applied to the purification of whey proteins from the polymeric and saline phases of aqueous two-phase systems. Process Biochem. 39, 1751-1759, http://dx.doi.org/10.1016/j.procbio.2003.07.002.
Silva, C.A.S., Coimbra, J.S.R., Rojas, E.E.G., Minim, L.A., da Silva, L.H.M., 2007. Partitioning of caseinomacropeptide in aqueous two-phase systems. J. Chromatogr. B 858, 205-210, http://dx.doi.org/10.1016/j.jchromb.2007.08.033.

Silva, C.A.S., Coimbra, J.S.R., Rojas, E.E.G., Teixeira, J.A.C., 2009. Partitioning of glycomacropeptide in aqueous two-phase systems. Process Biochem. 44, 1213-1216, http://dx.doi.org/10.1016/j.procbio.2009.06.016.

Silva, L.H.M., Coimbra, J.S.R., Meirelles, A.J.A., 1997. Equilibrium phase behavior of poly(ethylene glycol) + potassium phosphate + water two-phase systems at various $\mathrm{pH}$ and temperatures. J. Chem. Eng. Data 42, 398-401, http://dx.doi.org/10.1021/je9602677.

Steijns, J.M., van Hooijdonk, A.C., 2000. Occurrence, structure, biochemical properties and technological characteristics of lactoferrin. Br. J. Nutr. 1 (84 (Suppl.)), S11-S17.

Tubío, G., Pellegrini, L., Nerli, B.B., Picó, G.A., 2006. Liquid-liquid equilibria of aqueous two-phase systems containing poly(ethylene glycols) of different molecular weight and sodium citrate. J. Chem. Eng. Data 51, 209-212, http://dx.doi.org/10.1021/je050332p.

Ward, P.P., Paz, E., Conneely, O.M., 2005. Multifunctional roles of lactoferrin: a critical overview. Cell. Mol. Life Sci. 62, 2540-2548, http://dx.doi.org/10.1007/s00018-005-5369-8.

Zaslavsky, B.Y., 1995. Aqueous Two-phase Partitioning: Physical Chemistry and Bioanalytical Applications. Marcel Dekker, New York. 